\title{
Parental lip-smacks during infant mealtimes
}

\section{Multimodal features and social functions}

\author{
Sally Wiggins and Leelo Keevallik \\ Linköping University
}

The lip-smack is a communicative sound object that has received very little research attention, with most work examining their occurrence in nonhuman primate interaction. The current paper aims to dissect the social potential of lip-smacks in human interaction. The analysis examines a corpus of 391 lip-smack particles produced by English-speaking parents while feeding their infants. A multimodal interaction analysis details the main features: (1) rhythmical production in a series, (2) facial-embodied aspects, and (3) temporal organisation. Lip-smacks occurred in prosodically grouped chains of mostly 3 or 5 particles, with accompanying facial expressions, and were coordinated with the infants' chewing. They highlight the mechanics of chewing while framing eating as a pleasant interactional event.

The paper contributes not only to the distinctly social functions of a sound object hitherto ignored in linguistics but also to research on interactional exchanges in early childhood and their potential connection to the sociality of nonhuman primates.

Keywords: infant, interaction analysis, lip-smacks, multimodal, primate interaction, sound object

\section{Introduction}

The sounds of eating are an auditory reminder of the bodily processes of food consumption: the movements of lips, jaws, and tongue co-ordinated to move food from mouth down into the alimentary canal. While there may be different cultural norms that at times call for an accentuation or diminishment of mouth sounds in adult interaction - the slurping of noodles or tea, for instance - when feeding infants some of these sounds can become a focus for engagement with eating. In particular, the lip-smack, understood here as a sound involving lips and 
tongue, typically used for imitating chewing food, is a case in point. As a feature of social interaction between parents and infants, the lip-smack is a socially consequential sound object that can occur in the specific interactional context of mealtimes. It has, furthermore, recently been suggested as evidence of the evolution of pre-linguistic capacities in nonhuman primates (Ghazanfar \& Takahashi, 2009). In this paper, we detail some of the features of lip-smacks as produced by English-speaking parents during infant mealtimes, with a particular focus on their rhythm, multimodal coordination, and social functions. The aim of the paper is to provide a detailed account of a sound object that has not yet been considered as part of (early) language, but which plays a significant communicative role in social interaction between adults and infants during mealtimes.

Lip-smacks are a label we use in this study to refer to a group of sounds that are produced by pushing the lips together and then pulling them apart with a deliberate motion, in combination with a tongue movement, resulting in labial, dental, or alveolar click sounds with occasional vocal elements immediately preceding or following, or forming a semi-conventionalized item, such as a nyom/nom. They constitute a sound object, i.e., "conversational objects with minimal semantic content" (Reber, 2012:12) even while including functionally similar and articulatorily different items (see Reber \& Couper-Kuhlen, 2020, on whistles). While clicks have been the focus of phonetic and prosodic research (e.g., Ladefoged \& Triall, 1994; Ogden, 2013, Wright 2011a), research into lip-smacks as a functional object has to date been surprisingly limited.

Where lip-smacks have been mentioned in literature, they are considered across disparate fields of work and are not always clearly defined. For instance, they have been observed in conversation as a turn-holding device to signal an intention to continue speaking (Hjalmarsson, 2011), though it is not clear how these lip-smacks relate to phonetically defined clicks. In speech detection software research, they have been defined as "a sound generated by pressing the lips together and then opening quickly" (Li et al., 2008:292), and in infant language development as 'bilabial gestures' (Diepstra et al., 2017; Locke, 2008). The potentially sensorial or intimate nature of these sounds has been mentioned in work on the Autonomous Sensory Meridian Response (ASMR; the pleasant tingling somatosensory effects that can occur in response to hearing certain soft noises or whispers, e.g., Anderson, 2015) and in Korean mukbang (livestreamed eating, e.g., Choe, 2019) though again there is no clear phonetic definition of these sounds in that work.

Considered as a sound object, there has been very little research on lipsmacks in human social interaction. There has, however, been considerably more research conducted on this behaviour in nonhuman primates. The definition of a lip-smack used in this field suggests that the focus is on a similar research 
object, notably the "rapid opening and closing of the mouth and lips, such that when the lips close they make an audible smacking sound" (Maestripieri, 1996a, p.1003). Although there are likely to be variations in how primate lip-smacks might differ from those produced by humans, the research in this field offers important insights, particularly regarding adult-infant interaction.

\subsection{Lip-smacking in nonhuman primates}

Overwhelmingly, research into nonhuman primate species suggests that lipsmacking is associated with affiliative or submissive behaviours (Bergman, 2013; Fedurek et al., 2015; Ferrari et al., 2006), such as during hugging or grooming interactions (Maestripieri, 1996b). For instance, Maestripieri (1996a) studied captive adult Pigtail macaque monkeys and observed that lip-smacks were often displayed in response to aggressive behaviour from more dominant monkeys and thus used to seek affiliation. The affiliative nature of lip-smacking has been argued to be an important aspect of socialisation, with even few-day old rhesus macaques able to imitate the gesture when produced by an adult human experimenter (Ferrari et al., 2006). De Marco and Visalberghi (2007) observed lip-smacking as one of the first facial expressions to develop in Capuchin monkeys at around onemonth old. Lip-smacks were typically performed by adult monkeys - other group members - toward infants who were feeding from their mothers, and the occurrence of lip-smacks seemed to decrease as the infants grew older. Ferrari and colleagues have also made observations of lip-smacking between mother-infant pairs with rhesus macaques that highlight interactional features that were most prominent when the infants were young, up to 2-3 months old (Ferrari et al., 2009). The patterns they noted were that: (1) lip-smacks typically occurred when the mother was holding the infant and actively seeking the infant's gaze, sometimes by turning the infant's face toward her own, and (2) when mother and infant were further apart, the mother would move her face toward the infant's, sometimes lowering and 'bouncing' in front of the infant.

Despite evidence that different modalities - vocal behaviour, facial and bodily gestures, olfaction - work together during primate interaction, it has been argued that much primate communication research has been unimodal, focusing on either vocal aspects or gestures as separate strands of research (Micheletta et al., 2013; Slocombe et al., 2011). For instance, Fedurek and Slocombe (2011) noted that most research on primate vocal behaviour is conducted amongst monkey species, whereas gestural work is conducted amongst the great apes. More recent work with chimpanzees has, however, begun to examine the multimodal features of lip-smacks in interaction. Unlike monkey species, lip-smacks in chimpanzees have only been observed during grooming sessions, and it has been proposed that 
the lip-smacking may serve an important function in coordinating and extending those sessions (Fedurak et al., 2015). In their study with chimpanzees in Uganda, Fedurak and colleagues noted that lip-smacks typically occurred during the first ten seconds of grooming, were produced by the 'groomer' when they were within visual gaze and occurred more often when grooming vulnerable body parts. As such, they appeared to function to reduce the possibility of the recipient terminating the grooming (see also van de Waal et al., 2013). There is limited but important evidence of the reciprocality of lip-smacks, in which an individual will produce a lip-smack in response to that produced by another (Ghanzanfar et al., 2013). Continuing on these developments, the multimodal interactional coordination and the temporal organisation of lip-smacking will be in focus for our study.

The findings on the multimodality of primate interaction have implications for theories of language evolution in humans. One of the interesting things about lip-smack production is that it does not require laryngeal movement and thus in most cases has no vocal component. This has led some to argue that lipsmacks might be an important early stage in the evolution of speech (Ghazanfar \& Takahashi, 2009; Ghazanfar et al., 2012; MacNeilage, 2008). Ghazanfar and colleagues $(2009,2012,2013)$ have observed that lip-smacks in nonhuman primates are accompanied with rhythmic facial movements and as such might be a precursor to the rhythmical nature of speech. Similarly, Pereira et al. (2020) measured the rhythmic cycles of chimpanzee lip-smacks which averaged around $4 \mathrm{~Hz}$ and thus within the range of human speech which is between 2 and $7 \mathrm{~Hz}$. In other nonhuman primate research, there has also been a recorded instance of vocalised lipsmacking in Geladas in the wild (Bergman, 2013) which results in a sound similar to speech. Known as a 'wobble', the vocalisation is produced during lip-smacking, and by males toward females during affiliative interactions. While the technology used to record the audio and visual elements of lip-smacks in nonhuman primates may not yet provide the amount of detail seen in prosodic and phonetic studies in humans, there are early indicators of potential similarities between lip-smacks across human and nonhuman species.

Research on lip-smacks in nonhuman primates therefore highlights the importance of rhythm, multimodality, and the relevance of the interactional context, for instance, as a way to affiliate with other adults or interact with an infant. Given the paucity of lip-smack research outside of prosodic and phonetic studies on human clicks, the insights from primate research provide a valuable startingpoint. 


\subsection{Non-lexical sounds in interaction}

Recent developments at the crossroads of linguistics, interaction analysis, and sensory studies have demonstrated the importance of non-lexical sounds for understanding interaction. Falling beyond the scope of linguistics, and neither classified as language nor gesture, non-lexical sounds have to date received very little research attention (Keevallik \& Ogden, 2020) though there is recent work on sighing (Hoey, 2014), moaning (Hofstetter 2020), and sniffing (Mondada 2020), among others. Regarding lip-smacks, it is important to distinguish them from similar sound objects considered in other interaction research. The audible parting of the lips (sometimes immediately followed by an in-breath) has been noted as a 'pre-beginning' to talk, which can "project the onset of talk, or the beginning of a (next) TCU or a turn" (Schegloff, 1996; 92: TCU here referring to 'turnconstructional unit'). Both form and function of this sound object are different to the lip-smacks considered in the current paper: the lip-parting is singular, not typically loud or extended, does not involve additional vocal elements, and functions to signal the potential start to a turn in talk.

Similarly, a click - the sound made when air is sealed in the mouth and then released quickly through a downward or backward movement of the tongue is often a singular sound that is not necessarily associated with eating practices. While clicks have been studied as part of Western or Southern African languages (e.g., Bennett, 2014), their presence as a feature of English has only recently been addressed (e.g., Reber, 2012; Wright, 2011a, b). Just as primate research has noted the differences between language observed in natural environments compared with experimental settings, so do methodologies in linguistic research have an important part to play in how clicks have been overlooked or dismissed. Up until the early 200os, clicks were thought mainly to convey the speaker's emotional state or stance, such as disapproval or annoyance, due to a reliance on the analyst's assumptions and a lack of data from naturally occurring conversation (see Wright, 2011a: 208). This has also at times been colloquially characterized as 'tutting', referring to "not just to the sound of a click, but also to the negative stance that clicking conveys" (Ogden, 2013:300). In contrast, the more recent application of conversation analysis to clicks in everyday settings has demonstrated how they are organised in relation to conversational turns and sequences (Ogden, 2013; Reber, 2012; Wright, 2011b). They can also play an important and subtle communicative role in interaction. As Ogden (2020; p.86) notes, "Clicks allow participants to display an orientation to the relevance of talk without committing themselves to the things that speech (and the concomitant word selection) commits them to." The lip-smacks in our collection feature labial, dental, or alveolar clicks and thus the current paper contributes to the functional analysis of these 
sounds in the English-speaking community. As will be seen in the analysis section, however, it is the rhythmical features of lip-smacks, their temporal organisation within eating interaction, as well as associated vocal elements and facial gestures that distinguish them from clicks produced in singular form.

The overarching aim of this paper is to examine the multimodal features of lip-smacks used by parents in infant feeding interactions, as another sound object with communicative function. In so doing, we hope to provide analytical means through which researchers in both human and nonhuman primate studies can examine these sounds in everyday interaction to promote our understanding of language phylo- and ontogenesis. By targeting an activity that is foundational for any living organism from birth, the work also contributes to the unpacking of the various embodied events that have previously been glossed as 'eating. The mundane processes and practices of consuming food can be broken down into, for instance, smelling (Mondada, 2020, Fele and Liberman, 2021), the coordination of utensils and mouth-opening (Negayama, 1993; Toyama, 2013), tasting (Mondada, 2018, 2020), chewing, and swallowing. When a person is either learning to eat or has some trouble eating - for instance due to a short-term or permanent decline in muscle function - eating is not always guaranteed to progress smoothly. It is in these situations that the component parts of eating become more visible, audible, and salient as well as instructable. Our work will thus also contribute to research on eating and the sociality of infant feeding in particular.

\section{Data and methods}

The data for this study comprise video-recorded infant mealtimes recorded in Scotland in 2014 by parents with their infants of 5 to 8 months old. In total, five families recorded their infant meals over a period of two to three weeks, and for four out of five families, it was their first child. The parents were all white and spoke English as their first language, though aside from their ages, no other demographic information was collected. Parents were given two cameras to record the meals, to ensure that the whole scene would be captured on film. This was not always adhered to, and some of the video footage includes only one camera recording or does not adequately show all participants. No external microphones were used, though the audio quality was adequate for the impressionistic auditory analysis, and sometimes even for instrumental measurements, undertaken in this paper, together with visual inspection of the speech organs. In order to capture all multimodal interactional details, the choice of examples used in the analysis section is based on the availability of clear visuals of both parents and infants. 
The study was granted ethical approval by the University of Strathclyde, and thereafter procedures were followed to ensure that the families involved remain anonymous. For each family, one parent was met in person to discuss the nature and procedure of the study. Written informed consent was gained from both parents on behalf of themselves and their infant; all families gave consent for disguised images to be used in research publications, and for short video clips to be used for academic presentations.

The video data were searched manually, through repeated viewings, for all instances of lip-smacks by parents, whether or not these were 'directed' toward the infant. Video clips containing lip-smack sequences were created and transcribed. A single lip-smack (LS) sound object is referred to in this paper as a lip-smack particle' (LS particle); these are mostly labial, dental or alveolar clicks (transcribed as .mp, .mts or .mpt, respectively), with softer or louder releases and various degrees of "squelchiness", additionally featuring protruded lips, and optional vocalized elements, occasionally forming relatively extensive combinations (such as .mtsa, u.mpts). We refer to these items as LS particles to draw attention to their variable nature, position as part of a series, and with different communicative functions from singular clicks (e.g., Ogden, 2013). Even syllables without clicks, such as nyom/nom, were included because of functional similarities, while lip partings (transcribed as . $m t$ ) - a regular corollary of eating - were excluded. A multimodal interaction analysis (Goodwin, 200o; Mondada, 2011) was used to interrogate the data and to study the mutual coordination of lip-smacks, eye gaze, facial expression, posture, food, and mouths. The method is designed to reveal how meaningful actions are brought about in a moment-by-moment deployment of various semiotic resources and achieve their meaning through the immediate (re)actions by co-participants. By analysing the temporal organisation of parental lip-smacks in relation to infant behaviour, using Elan, Audacity, and Praat software, we were thus able to reveal their precise social function. Transcription conventions follow the emerging tradition of multimodal interaction analysis, developed by Lorenza Mondada (https://www.lorenzamondada.net/multimodaltranscription).

\section{Analysis}

The analysis will detail the multimodal organisation and interactional coordination of lip-smacks within concrete episodes of parent-infant interaction. Table 1 provides an overview of the full collection of lip-smacks as they are distributed across the data corpus. 
Table 1. Distribution of lip-smack chains and particles across the data corpus

\begin{tabular}{lcccccc}
\hline $\begin{array}{l}\text { Family } \\
\text { codename }\end{array}$ & $\begin{array}{c}\text { Age } \\
\text { of } \\
\text { infant }\end{array}$ & $\begin{array}{c}\text { Meals } \\
\text { recorded }\end{array}$ & $\begin{array}{c}\text { Total recorded } \\
\text { time (h:mins) }\end{array}$ & $\begin{array}{c}\text { Meals with } \\
\text { lip-smacks }\end{array}$ & $\begin{array}{c}\text { Number of lip- } \\
\text { smack chains }\end{array}$ & $\begin{array}{c}\text { Number of } \\
\text { LS particles }\end{array}$ \\
\hline \#1_Ben & 7 mths & 16 & $08: 39$ & 1 & 5 & 33 \\
\#2_Lewis & 8 mths & 14 & $05: 55$ & 11 & 52 & 228 \\
\#3_McD & 5 mths & 9 & $01: 56$ & 5 & 16 & 70 \\
\#4_Small & 5 mths & 15 & $01: 35$ & 3 & 6 & 32 \\
\#5_Reilly & 6 mths & 12 & $00: 32$ & 4 & 6 & 28 \\
Totals & & $\mathbf{6 6}$ & $\mathbf{1 8 : 4 9}$ & $\mathbf{2 4}$ & $\mathbf{8 5}$ & 391 \\
\hline
\end{tabular}

What is immediately striking from the table is the varied distribution of lipsmacks across the different families. For instance, Family \#1 recorded many more hours of data than the other families though only one of these recordings contained lip-smacks. Most of the lip-smacks were produced by Family \#2 throughout most of their recorded mealtimes (11 out of 14). Although each LS particle and chain may have its own nuance in terms of production - examples of these will be shown in the analysis - the sounds consistently involve lips, clicks, repetition, and coherent rhythmic structures. Furthermore, while there is diversity across this distribution, one thing is clear: lip-smacks were found across all five of the families. The total number of LS particles (391) is itself noteworthy.

Before detailing the multimodal features and social functions of the sound object, we will first illustrate a typical example of lip-smacking, while the parent is intermittently also licking their fingers, in Extract 1. This instance was chosen to demonstrate specifically that the finger-licking lip-smacks are qualitatively and organisationally different from the non-licking ones, not least of which, it is often the difference between a single bilabial click and a series of repeated LS particles. Even though finger-licking can be oriented to by the co-present other it is not necessarily so. In other words, lip-smacks may be either a by-product of eating and finger-licking or performed as a repeated and purposeful series, with an option to transform the first one into the second type. In this mealtime, Mum and infant are eating breakfast together and Mum is in the process of moving some food closer to the infant.

\section{Extract 1. Lewisoo2_0515}

\begin{tabular}{|c|c|c|}
\hline 01 & INF & $\mathrm{mmh}$ ? \\
\hline ว2 & inf & $\begin{array}{l}\text { >>searching for a bite on the tray } \\
(\theta .5)^{\wedge}(\theta .4)\end{array}$ \\
\hline & mum & reaches over to the tray->1.09 \\
\hline 93 & MUM & want that bit over there, \\
\hline & inf & Slifts a handful \\
\hline
\end{tabular}


${ }^{\circ} \mathrm{mmh} .^{\circ} \&$

06

$$
\text { (1.0) }
$$

$(0.6)^{\wedge}(0.7) \&$

gaze to inf-->1.15

\&same piece of food has come back out

09

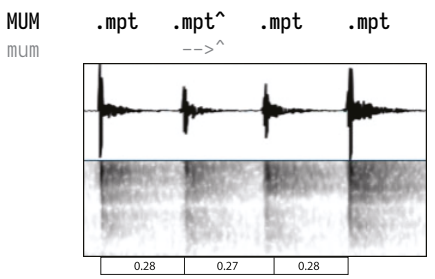

Image 1: wave form and intervals in seconds

$(0.2) \&(.)^{\wedge}($.

\&gaze to mum $-\rightarrow 1.12$

${ }^{\wedge}$ finger to mouth

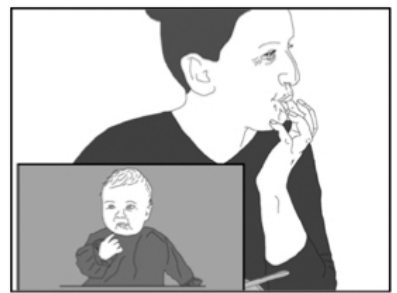

Image 2: finger lick

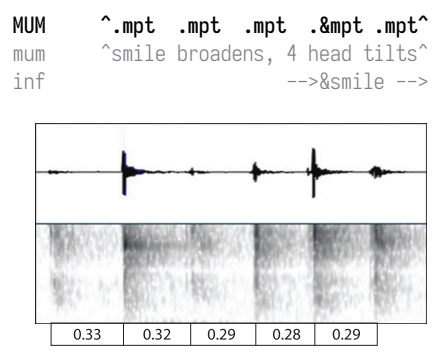

Image 3: wave form and intervals in seconds;

beginning with the finger-licking in line 11

^(.)\%(1.0)*\&

^open smile*

\%gaze down 


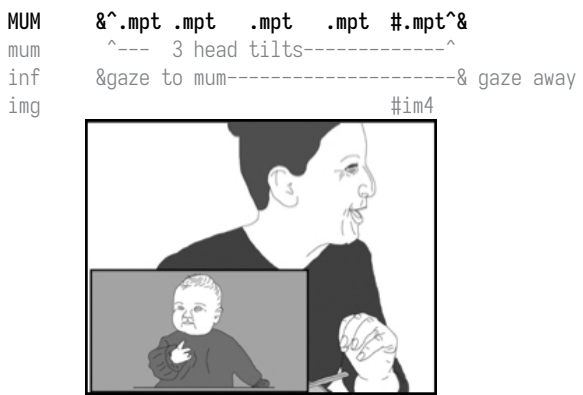

Image 4: head tilt, smile

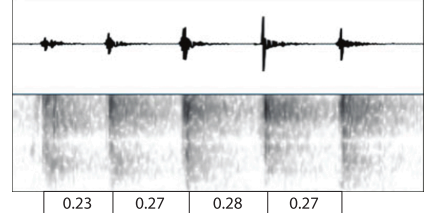

Image 5: wave form and intervals in seconds

$(2.5) \&(0.5)^{\wedge}$

mum $\quad$ \&licks fingers

gaze inf $\rightarrow^{\wedge}$ gaze to own plate, smile disappears

This first extract illustrates a single bilabial click that accompanies the licking of a finger (line 11) as well as three chains of lip-smack particles in close succession to each other (lines 9, 12, 14). ${ }^{1}$ As with many of the instances in the collection, there is a verbal pause both immediately before and after the lip-smack chains, which distinguishes them from the surrounding talk turns. The single fingerlicking smack occurs as a prosodically individual item and is subdued in relation to the others (see Image 3); it is softer and does not feature a dental or alveolar click sound. The chains, in contrast, involve alveolar clicks and five items each; they feature loudness on a par with speech and form rhythmically coherent contours that are somewhat varied on each chain (see Image 1, 3, 5). The fingerlicking furthermore emerges as relatively brief and quickly transforms into a new chain of five LS particles, which posthumously recontextualizes even the fingerlicking sound as being part of a performed set of lip-smacks with a coherent contour. There are thus systematic differences in prosody, repetition, and rhythm between individual finger-licking lip-smacks and those performed in orientation to another person.

Furthermore, the two categories differ regarding the accompanying gaze behaviour. Throughout the three series of performed LS particles, Mum's eye gaze is steadily on the infant, constituting a clear interactional space between them.

1. Note also that Mum also licks fingers in line 15 but this time no sound can be discerned, which shows that fingers can be licked so that no sound escapes. 
She turns her gaze to the infant part-way through her withdrawal of her hand in line 8 while the infant still seems to be gazing into the void. They slightly raise their eyes after the first chain of LS particles in line 9-10, whereby mutual gaze has clearly been established. Mum, accordingly, finds herself gazed at while licking her finger in line 11 (Image 2), which may occasion her rapid transition to the next interactional LS chain. During the second chain in line 12 there is thus mutual gaze already at the start. Likewise, mutual gaze is re-achieved at the very beginning of the third LS chain in line 14. Mum holds her gaze on the infant during lines 8-15, at which point she looks down to her own food. Based on this regularity in our collection, it is reasonable to assume that LS chains are parental tools for achieving and maintaining mutual visual orientation and social engagement during infant mealtimes.

There are also distinct bodily aspects of the production of some of the LS chains. Mum's eyes widen as the finger-lick is completed (1.11; Image 2), and in combination with the second LS chain (line 12) she leans in and tilts her head from side-to-side, further animating the production. The third LS chain repeats this animation (line 14) and ends with Mum's head and shoulders moving slightly forward and down in the direction of the infant (see Image 4). Aspects of the temporal development of embodied behaviour are summarized in Table 2, with the help of symbols to characterise the facial gestures and bodily movements. Taken together, this is an episode in which the lip-smack sound is not only produced audibly but also accompanied by a visible display; this underlines the social potential of LS particles as devices for adult-infant interactional engagement. Crucially, many LS chains are produced in response to displays of possible trouble, such as food coming out of infant's mouth, as happens in line 8. This is immediately followed by the parent's LS chain, thus emerging as an interactional sequence of trouble display and offering a potential solution (food can be transported inside the mouth through lip movements).

Having considered an example, the rest of the analysis will detail the main features and functions of lip-smacks, specifically focusing on, (1) rhythmic production, (2) facial-embodied aspects, and (3) temporal organisation.

\subsection{The rhythmic and prosodic production of lip-smack chains}

It is the rhythmical feature of lip-smacks that characterises them as interactional lip-smacks and distinguishable from solitary bilabial clicks. While other sound objects might also be repetitive (e.g., Ogden, 2020), lip-smacks are perhaps distinctive as a social object only when they are repeated in a rhythmical pattern. The rhythm of LS particles is therefore produced through their presence as a series of articulatorily similar tokens. We refer to these as LS chains, since the particles 
Table 2. Transcript lines 09-12 (Extract 1); LS particles aligned with infant's chewing motions $(\mathrm{C}=$ closed mouth; $\mathrm{O}=$ open mouth), the temporal development of facial expressions, and posture

\begin{tabular}{|c|c|c|c|c|}
\hline & line 09 & line 10 & 11 & line 12 \\
\hline Mum &. $\mathrm{mpt} \cdot \mathrm{mpt} \cdot \mathrm{mpt} \cdot \mathrm{mpt}$ & &. $\mathrm{mp}$ & $. \mathrm{mpt} . \mathrm{mpt} . \mathrm{mpt} . \mathrm{mpt} . \mathrm{mpt}$ \\
\hline $\begin{array}{l}\text { inf } \\
\text { mouth }\end{array}$ & C $\quad$ O $\quad$ C & $\mathrm{O}$ & & $\mathrm{O}$ \\
\hline $\begin{array}{l}\text { inf } \\
\text { gaze }\end{array}$ & & to mum & & \\
\hline $\begin{array}{l}\text { mum } \\
\text { eyes }\end{array}$ & & & & \\
\hline $\begin{array}{l}\text { mum } \\
\text { head }\end{array}$ & & & & \\
\hline $\begin{array}{l}\text { mum } \\
\text { smile }\end{array}$ & & & & \\
\hline $\begin{array}{l}\text { inf } \\
\text { smile }\end{array}$ & & & & \\
\hline $\begin{array}{l}\text { mum } \\
\text { lean }\end{array}$ & 象 & & & \\
\hline
\end{tabular}

are uttered rapidly after each other and hearable as forming a coherent prosodic unit. The length of lip-smack chains with number of LS particles per chain was counted across the data corpus (see Figure 1), and all but three LS particles were in a chain of between 2 and 10 particles in length. Notably, around one-third of all chains in the corpus contained five LS particles, with the next most common length being three LS particles. Of the three solitary LS particles, one was produced with finger-licking (Extract 1 ) and the other two were followed by a vocalised outbreath 'ahh' sound: in these latter cases, the lip-smack was arguably part of a different sound object.

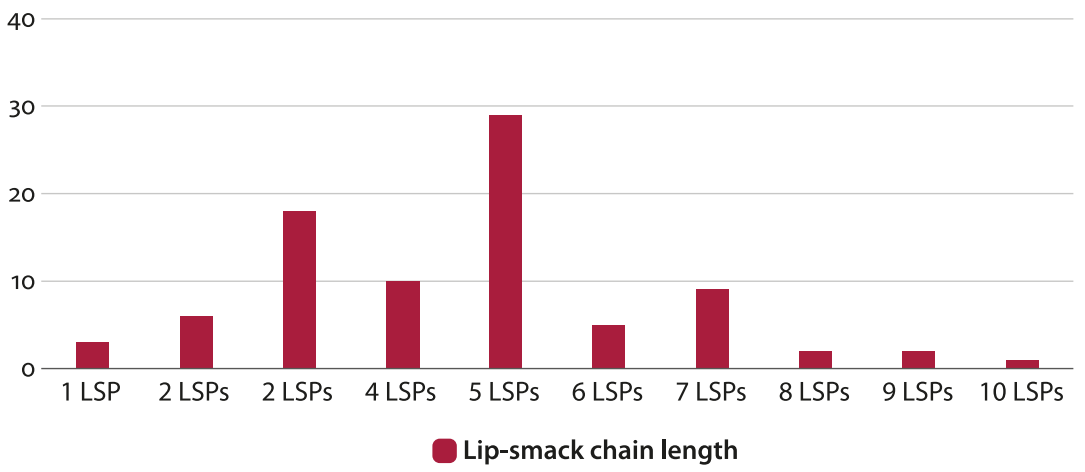

Figure 1. Length of lip-smack chains in the data corpus 
The regularity of three or five LS particles in a chain constitutes a major feature of interactional lip-smacks. Since they are produced through a closing-thenopening of the mouth, the tempo of production of lip-smacks as a chain is in part dependent on the pace at which a person can move their jaw and lips. Unlike vocal tract sounds that can be extended by passing more air through the vocal folds, the stop-like nature of many LS particles means that it cannot be extended in the same way and the repetition may thus serve for purposes of extension. Furthermore, the tempo of the LS chains in the data corpus was seen to fluctuate in relation to the nature of the action. The next two extracts illustrate a faster and slower tempo of LS chains. Extract 2 shows an episode just before the beginning of feeding where the LS chain is uttered approximately at the pace of the surrounding talk.

Extract 2. Smaoo1_0037
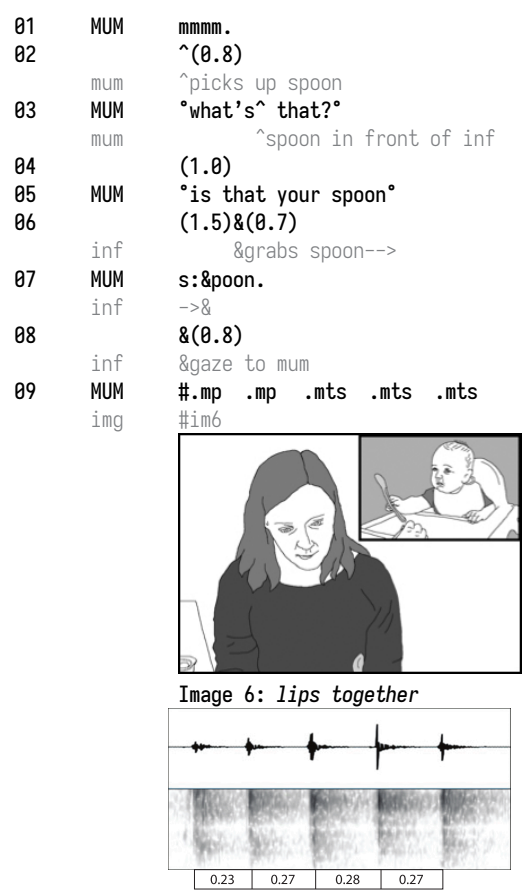

Image 7: wave form and intervals in seconds

$(). \&(.)^{\wedge}(0.4)$

\&drops gaze and spoon

^drops gaze

11 MUM

will we have some breakfast

(2.0)

As with Extract 1, there is a brief pause before and after the LS chain, with both Mum and infant holding eye gaze and position: neither moves during the production of the lip-smacks. They both then disengage eye-contact in line 10 as Mum 
raises her hand to her hair, and the infant's hand and eye gaze lower toward their food tray. Mum then utters 'will we have some breakfast' as she turns to pick up the infant's food. The lip-smacks here are thus uttered in the preliminary phase of the meal, before any food has been consumed, but when the preparatory work of holding the spoon is in place. The LS chain is thus positioned as a possible explanation of the meaning of the lexical item spoon through its use for the mouth, and projecting an activity related to this tool. The tempo of this lip-smack is broadly in line with the surrounding talk, and of a similar volume, thereby enhancing its hearability as part of an explanation of what a spoon is good for.

By contrast, a variable tempo LS chain can be used when eating is already in progress, arguably to match the actual or potential chewing pace of the infant. In Extract 3 below, the infant is eating in a seated baby-walker while Mum kneels on the floor nearby. The movement of the baby-walker means that the infant is mobile and Mum occasionally adjusts the position of the walker, thus making mutual visual engagement possible. Immediately prior to the lip-smacks there is a series of verbal 'yum's from Mum which have a similar pace and rhythm to the subsequent lip-smack chain on line 10 and 19.

\section{Extract 3. Reillyoo9_0204}
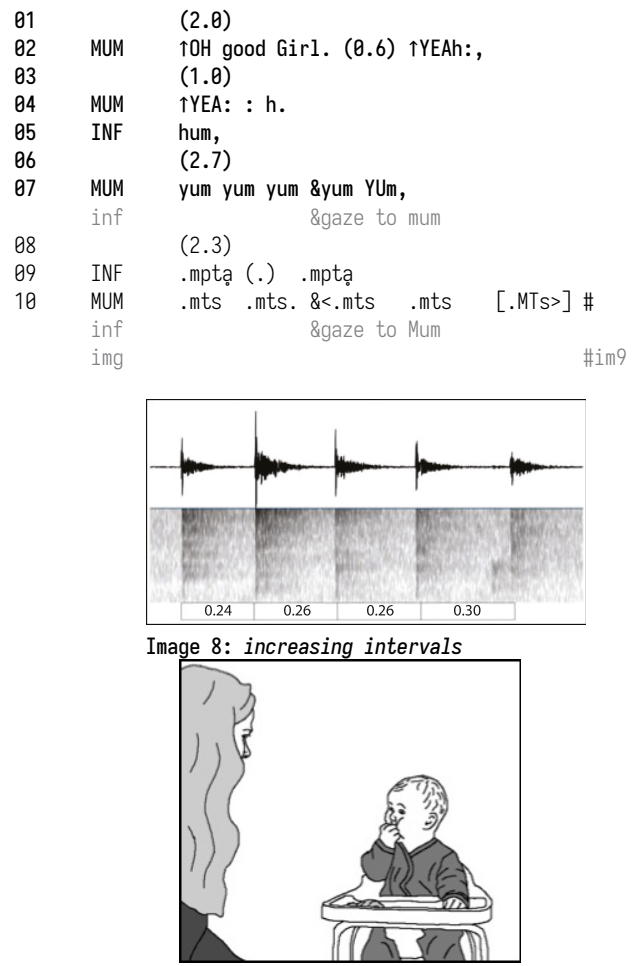

Image 9: mutual gaze 


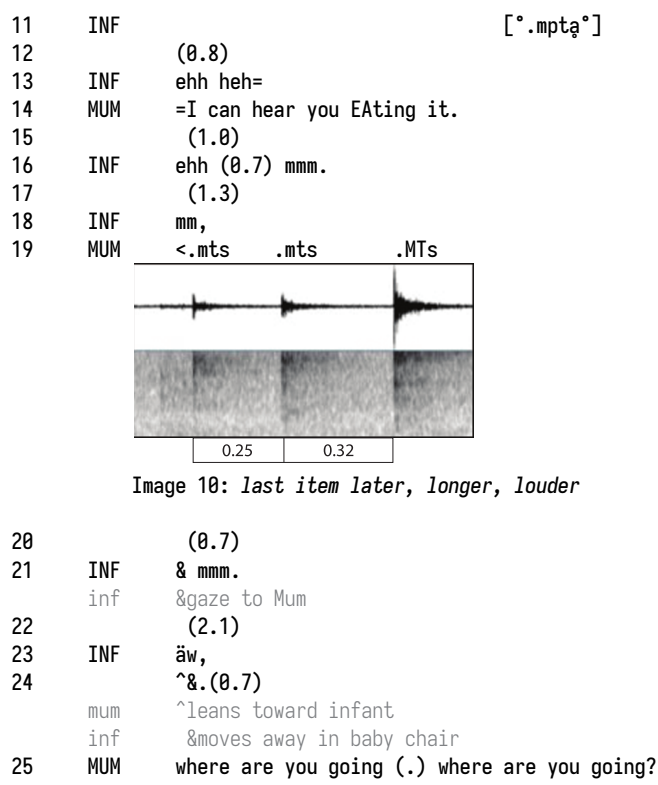

At the start of the extract, Mum offers praise and encouragement, possibly to acknowledge the infant's self-coordination of hand, mouth, and food: a small but important step toward eating independently. The praise is given with high pitch and smiley voice. The infant smiles in return - with hand still in mouth - and there is a breathy noise on line 05 that could be something like a laughter particle from the infant. Rather than moving onto a different topic, the subsequent series of 'yum's (line 07) and lip-smacks (lines 10 and 19) function to prolong the engagement with the infant's eating without requiring any response from the infant. The LS particles are locally responsive to the infant's arguably instrumental eating sounds (lines $09,16,18$ ) and work a little like a running commentary of the activity (cf. line 14) while also engaging in the actual eating movements as if the speaker were part of the process. The infant continues by moving their jaw and holding the hand in mouth, thus complying in the extension of the eating event. The lip-smacks seem to provide a means through which the parent can 'join in' the infant's eating activity when not eating themselves, both simultaneously with the chewing and sequentially responding to infant eating sounds, thus constituting it as a social occasion.

The pace of the lip-smacks in this example mirror the tempo of the 'yum's at the beginning and slowing down by the end (see Image 8), possibly adjusting to the considerably slower pace of infant's current chewing and resulting in the last item being uttered in synchrony with the infant's lip-smack (lines 10, 11). The 'yum's and the first LS chain sound prosodically similar. In contrast, the last chain of three lip-smacks (line 19) is produced with the very last item both slower 
and louder (see Image 10). Even though slightly different, they all constitute clear rhythmic patterns. As with the previous extracts, Mum's eye gaze is on the infant throughout. The infant turns their gaze to Mum during the LS chain (during the third LS particle in the first chain, line 10; see Image 9) and soon after it (in line 21 after the second chain), achieving mutual visual orientation. The chain of 'yum's also attracts the infant's gaze by third repetition. We can thus also here see the prosodically parallel use of a lexical vocal item (such as 'yum') and a LS particle, as well as perhaps a gradual reduction in the prominence of the item repetitively produced to accompany infant eating: from a lexical item to a non-lexical sound, from more to fewer repetitions.

To summarise, parental lip-smacks almost exclusively featured a chain of rhythmically produced LS particles, with the most frequent chain length being five particles. Rhythmic variability allows for flexibility in the timing and function of the LS chains, with differing tempos that can in some cases mirror the pace of the surrounding speech or infant chewing. Furthermore, as noted previously, the rhythm of primate lip-smacks (averaging at $4 \mathrm{~Hz}$ ) makes them similar to speech (Pereira et al. 2020) and this may turn out to be relevant also in infant-addressed vocal sounds. Not only do lip-smacks have an acoustic rhythm that is similar to speech and usable for turn-taking as in Extract 3, but the facial movements of the lips and jaws are also vividly synchronised with the sound, making them visually salient for the recipient. The lip-smacks functioned in some instances to encourage eating through jaw movements and enacted sociality in eating through vocally participating in the infant's embodied actions. In fact, LS chains are systematically associated with other multimodal features including eye gaze and postural shifts, which we detail in the following section.

\subsection{Eye gaze, facial gestures, and embodied movements}

The production of LS particles is not only characterised by vocal features but also markedly by embodied gestures and movements. Most notably, in all of those LS chains where faces were visible on the video (67 out of 85 ), parental eye gaze was on the infant for the duration of the LS chains. This is reminiscent both of other sounds used between human parents and infants (Wiggins, 2019; Wiggins \& Keevallik, 2021) and lip-smacks observed in primate parent-infant dyads (Ferrari et al., 2009; Fedurak et al., 2015). Fixating their gaze on the infant, particularly during the production of a sound that orients to mouth movements, is a way in which a parent can enact eating on behalf of their infant. Furthermore, LS chains may be attentive to and even instructive of the jaw and tongue movements necessary for eating. 
The parental eye gaze was, in around three-quarters of instances, reciprocated by the infant even if their eye gaze was not consistently on the parent. In around half of the LS chains the infant was already gazing at the parent when the chain began; in the rest, their gaze shifted to the parent either during or immediately following the lip-smack. Instances of this can be seen in Extract 1 and Extract 3. In all these cases, the LS chains occasion a shared intersubjective space between parent and infant. Lip-smacking may thus be useful for achieving a visual focus on the parent's face and mouth, and modelling jaw movements.

In addition to eye gaze, other facial gestures and embodied movements often accompanied the lip-smacks, at times exaggerating and expanding the sounding practice through the enhanced movement of the lips, the use of eyebrows, and head tilts. In Extract 4, we see an example where Mum is trying to encourage the infant to eat when there seems to be possible reluctance from the infant (see also Wiggins \& Keevallik, 2021); it begins with Mum trying to ascertain whether there is any food in the infant's mouth.

Extract 4. McDoo3_0424

01 mum here let's see, (0.2) ^ah:, (.) open wide.

^opens mouth, head slightly back

(日.9) ((Mum tries to look into infant mouth))

03 mum I know that you're too small to do that 'though,

04

$(0.4) . n h s(.)^{\wedge}(0.2) \&$

$\rightarrow \wedge$ gaze to bow]

'gaze to inf $-\rightarrow>$

mum

05

\&gaze to mum's eyes

$(1.7) \&(1.0) \&$

\&opens and closes mouth\&

06 mum

\& .mpt *.mpt. \#mpt ^.mpt\&* .mpt .mpt

\&opens and closes mouth\&

*gaze to mum's mouth* gaze back to eyes

^smile develops

img

\#im11

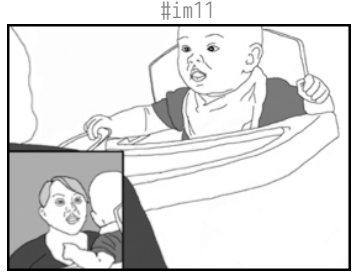

Image 11: joint mouth movement

\&.Mpt (0.3) .Mpt (0.3) \#.Mp[t (.)](0.3).Mpt

\&lips pushed together

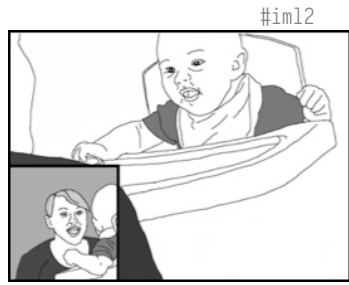

Image 12: infant smile develops 


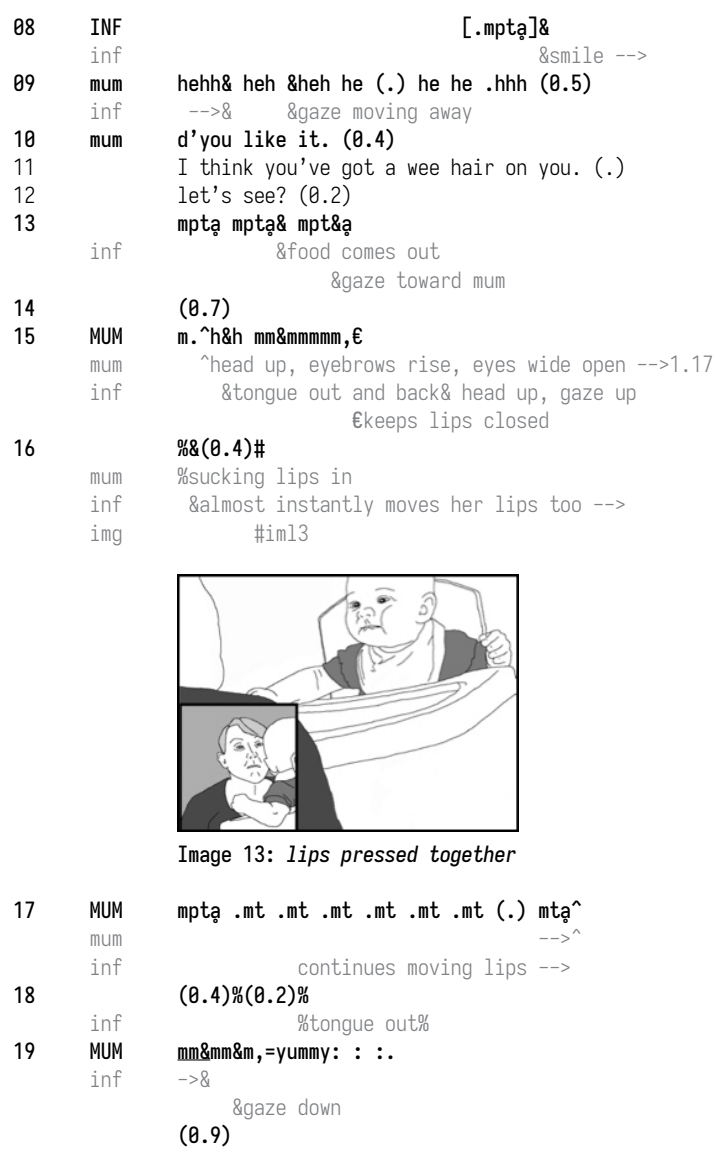

The concern with whether or not eating is occurring is reflected in Mum's body positioning: not only is she facing the infant but also leaning forward and downward, diminishing the distance between them so that their faces are almost level with each other. In this position, Mum utters the LS chains (lines 06, 07, 13, 17) with an exaggerated opening and closing of the mouth (see Images 11, 12, and 13). Furthermore, several LS particles end in a broad mouth opening, especially in lines 13 and 17 (transcribed as voiceless $a$ sounds). They are thus performed in a highly visible manner. In addition, the LS chains in this extract are slowed down to a greater degree than in previous examples (with the intervals from 0.22 at the beginning of line 06 to 0.54 seconds at the end of line 07) and feature a qualitatively different prosodic contour without a projectable end. They form a constant stream that is therefore also extendable, which allows them to be paced alongside emergent infant actions and their temporal structure (see Table 3 regarding the timing of the infant's jaw movements). Furthermore, in line 16 the infant moves their lips almost instantly after Mum has sucked her own lips inward and her LS particles in line 17 may be occasioned by the infant's lip movements, as they con- 
tinue alongside those and ultimately emerge as a stream of eight LS particles (see Image 12).

These types of highly pronounced and extendable LS chains are used to encourage the infant to either open their mouth or to make chewing motions. This is particularly the case with the chain on line 13 which comes immediately after the 'let's see' request to see what food is in the mouth and leads to the infant pushing out food. At other moments the LS chains facilitate the infant joining in with various lip movements: they either move their lips (lines $06,16-17$ ) or push their lips together (line 07). The LS chain on lines $06-07$ slows down even further before the final particle, suggesting waiting for the infant after they have stopped moving their lips. Indeed, the infant does open their mouth in synchrony with a lip-smack from Mum (lines 07-08), and combined with the infant's smile, this might be what occasions Mum's laughter on line og (see Table 3 for the temporal emergence of those behaviours). There is thus evidence of fine coordination of jaw movements between the infant and the parent during the lip-smacks, supporting the argument that they can be used for socialization into eating practices.

Table 3. Transcript lines o6-o8 (Extract 4); Acoustic and temporal representation of LS particles

\begin{tabular}{|c|c|c|c|c|}
\hline \multicolumn{5}{|c|}{ 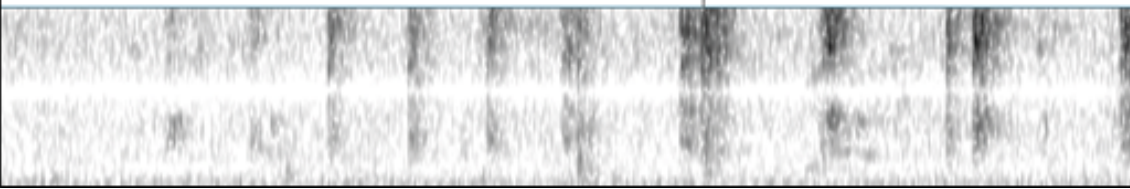 } \\
\hline & line & & line 07 & line 08 \\
\hline Mum & .mpt .mpt. mpt. mpt & .mpt .mpt & $. M p t . M p t$ &. Mpt $\quad$. Mpt \\
\hline Inf & & & & .mpt à \\
\hline inf & 0 & C & & 0 \\
\hline mum & head up $-->$ & & & \\
\hline inf & head up $-->$ & & & \\
\hline inf & gaze M mouth & to $M$ eyes & $-->$ & \\
\hline mum & smile & $-->$ & & \\
\hline inf & & & & smile \\
\hline
\end{tabular}

Other embodied features include Mum's stable gaze on the infant and head raises. Mum's constant inquisitive visual focus on the infant seems to successfully attract their attention in the form of gazing back towards Mum and returning the smile (line 08). During the LS chains in lines $06-07$ and 17 as well as the gustatory 
mmms (line 15), when there is mutual gaze, Mum's head raises slightly and again this is mirrored by the infant's slight head movements that follow almost immediately. In short, even though there appears to be not much left in the infant's mouth, the coordinated jaw and lip movements between Mum and infant achieve something like joint eating. Through smiles, Mum's laughter, raised eyebrows and lexical items such as "yummy", the eating experience is furthermore framed as a pleasant one. The highly salient vocal and embodied production of LS particles constitute an essential part of this achievement.

In the next example (Extract 5), there is an even more emphasised series of LS chains combined with the conventionalized 'nom nom' item and pronounced facial gestures that focus attention on the movement of the jaw and lips. This is also an example where the parent is eating and produces all the LS particles while they have food in their mouth.

\section{Extract 5. Lewisoo4_0940}

01

02

INF

inf

03

04

05

06

07

08

INF

09

10
(12.0) ((infant eating, some vocalization))

quh (.) quuuh .MPT

>>chewing

huh .mptạ .mpt

^(1.0)

^leans toward infant

.mpt=nom $\quad . m p t=n o m ~ . m p t=\&+n o m ?$

chewing $\quad->$ \&gaze to Mum $->>1.08$

+mouth wide open-->

he: $+=$

$-\rightarrow+$

$=^{\wedge} \& . \mathrm{mpt}=$ nom $. \mathrm{mpt}=\mathrm{nom} \quad . \mathrm{mpt}=[\mathrm{nom} ? \&$

^smile-->1.12

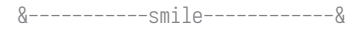

[waw \&aw

-->\&gaze down

.mptam\&=. mtnam?

$->\&$

$(1.8) \&(0.2)$

inf \&gaze to Mum, chewing motion

MUM hmm.mptnom .mptnom .mptnom:?

inf three chewing motions

INF \&mmh (0.3) \&^

$\&--$ smile $--\&$

smile-->^

^\&. ${ }^{\circ} \mathrm{mpt}{ }^{\circ}$

mum ^eyes wide-->

$(0.7)^{\wedge}$ 


$\begin{array}{lll}16 & \text { INF } & \text { mh (0.8) } \\ 17 & \text { MUM } & \text {.mpt } \\ 18 & \text { INF } & \text { \& }^{\circ} \text { uh eh } \\ & \text { inf } & \text { \&leans forward to grab Mum's nose }\end{array}$

The excerpt begins with the infant sounding while eating and producing some lipsmacks (lines 02-03). Mum's first LS chain follows up on this, as if responding to the infant's eating sounds and making them socially relevant through her exaggerated repetition of the "same" sounds (line 05). While the infant's LS particles are probably instrumental, at least seemingly a by-product of the mastication of food, Mum's LS particles are uttered with an intense embodied focus, achieved through widening and holding eye-gaze and leaning in towards the infant. They furthermore feature an elaborate structure, with lengthy voiced components ('nom'), and a notably louder volume than the infant's sounds. Mum's salient performance attracts the infant's gaze towards the end of the chain (line 05), when the infant also opens their mouth. As with Extract 4, there is evidence of the coordination and achievement of joint jaw movements, thus eating.

In response to the infant's gaze and mouth-opening Mum launches a next LS chain, which is similarly coherent, likewise consisting of three near-identical items, and featuring a prosodic contour that rises in the end (line 07; unfortunately, the audio quality does not allow for instrumental measurements). Towards the end of this chain the infant lowers their gaze and Mum produces a single item without infant orientation (line 09). However, as soon as the infant raises their gaze back to Mum and makes some chewing motions, she utters a third LS chain (line 11), which is phonetically and prosodically very similar to the previous ones, relatively slow in pace (with intervals of $0.4-0.5$ seconds). Importantly, we can also see how Mum's LS chain is responsive to the infant's attention as well as jaw movements, arguably enhancing and encouraging them in real time. The infant is then doing regular chewing motions in near synchrony with the Mum's exaggerated LS particles (line 11, see Table 4): they are performed with protruding lips, forward lean, broad smile, and vocalized between the click sounds. Mum can thus be heard and seen as if sonifying the bodily experience of the infant. In response, the infant vocalizes with a labial sound similar to Mum (line 16, as well as 12), resulting in something reminiscent of turn-taking, albeit merely with (chains of) LS particles.

Mum's prosodic production of the four chains is in this excerpt clearly in the form of coherent rising pitch contours, enabled by the voiced sounds in the 'nom's. Functionally, they build an extended and recurrent engagement with jaw and tongue movements, thus also food. Similar to Extract 3, LS particles do not appear to function as prompts to start chewing, as the infant is already chewing or masticating. Instead, they reflect Mum joining in the eating activity and perhaps framing it as a pleasant shareable experience through her various bod- 
Table 4. Transcript lines 11-12 (Extract 5); Acoustic and temporal representation of LS particles; $(\mathrm{O})=$ half-open mouth

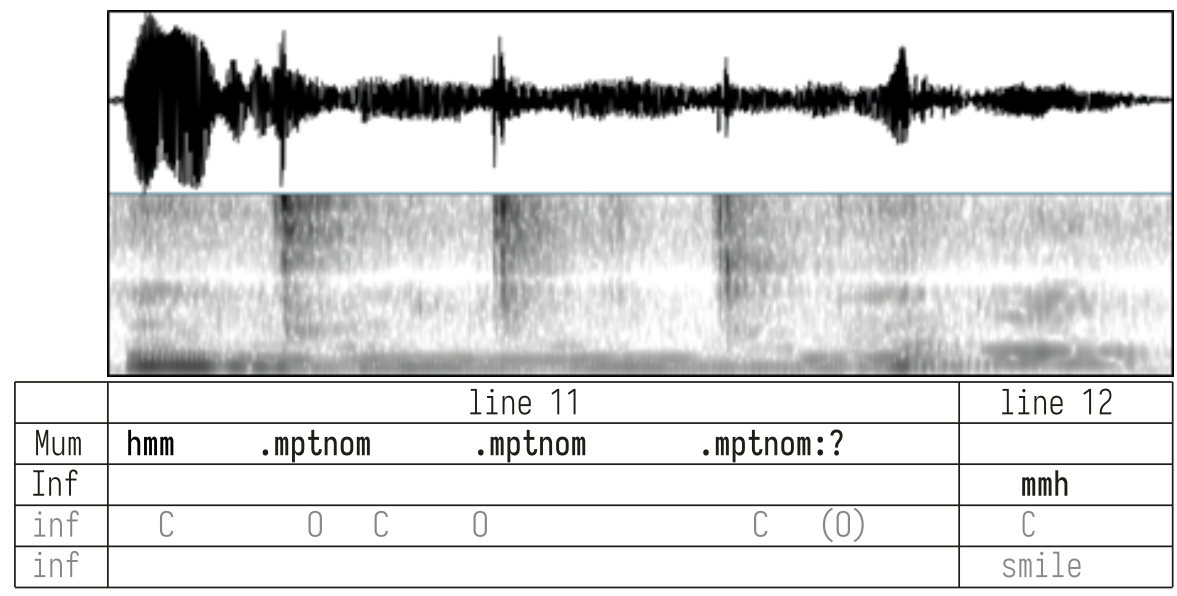

ily displays. Her LS chains work to both attract the infant's gaze but also hold the intimate mutual orientation and accomplish matching next turns in response to infant sounds. Through a variety of embodied means, lip-smacks thus constitute sociality while eating.

To summarise, the LS chains were not only produced prosodically in rhythmic patterns but also characterised by parents holding eye gaze on the infant throughout the duration of their production. In addition, other regular embodied features also occurred: there was often mutual eye-gaze achieved at least for part of the lip-smack sound, the parent would sometimes widen their eyes with or without a raising of eyebrows, typically leaning in toward the infant, smiling, and occasionally moving their head from side-to-side during the lip-smacking. Collectively, these embodied actions work to animate the LS chain and demonstrate the social relevance of the sound and actions as a means through which to engage the infant in the practices of eating.

\subsection{Temporal organisation}

In this section we further elucidate the organization of lip-smacks with respect to their temporal coordination with eating practices. LS particles always occurred in the first position of a speaker turn in our data corpus. Like other non-lexical sounds, they do not necessarily make relevant a particular response, though as seen in Extract 3 and 5, they can nevertheless be responsive to others' lipsmacks, with parents producing them in enhanced versions after infants' audible lip sounds. They therefore seem to create and make use of an interactional space 
in which verbal conversation is suspended while eating continues. In the final two extracts we illustrate how LS chains are organised temporally in relation to other activities during the infant mealtimes. The most prevalent, of course, is the activity of the infant's eating. The parent is also on occasion eating at the same time, and thus the LS particles need to be co-ordinated with the manipulation of food in their mouth. In such cases, it is possible to see on the parental faces the outline of food being moved toward the back of the mouth and/or swallowed to enable the LS particle to be produced. The combination of jaw and tongue movement required to produce a LS particle means that the mouth needs to be almost completely empty before the sound can be adequately produced. This means that, perhaps ironically, while lip-smacking arguably orients to the other's chewing process it is not possible to chew oneself while uttering LS chains. Not only are LS chains therefore organised in relation to conversation but also, even primarily, the progress of eating.

In Extract 6, there is a clear example of this movement on the parent's face and throat. This parent-infant duo is the same as seen in Extract 4; the infant's eating is slow at times, and this perhaps prompts Mum's questions on lines 01 and 03.

Extract 6. LSo8_McDoo7_0820

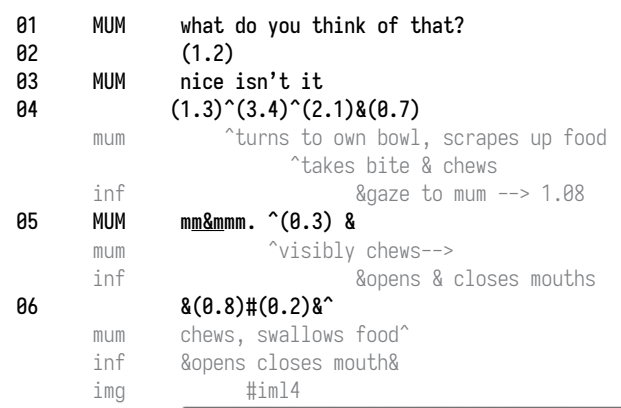

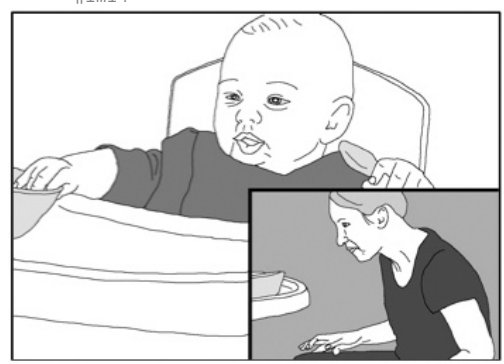

Image 14: swallow

.mpt.mpt\&.mpt.^mpt.mpt\&

$\wedge$ develops smile 
The infant is holding a spoon in their left hand and at times grabbing a bowl in their right hand, with eye gaze moving between the two objects. It is when Mum starts to eat her own food (line o4) that the infant then gazes up toward Mum and they achieve mutual eye gaze. With food clearly visible in her mouth, Mum puts down her bowl and produces a gustatory $\mathrm{mmm}$ (line 05) while continuously chewing. As the $\mathrm{mmm}$ is produced, the infant opens and then closes their own mouth, with hands still on spoon and bowl, and eye gaze fixed on Mum. After a brief silence (line o6), Mum then swallows her food (Image 13) - maintaining eye gaze throughout - and thereafter produces the chain of five LS particles (line 07), smiling toward the end.

As with the previous extracts, there are multimodal elements to this LS chain that orient to social functions: mutual eye-gaze, smiling, and leaning in toward the infant. In addition, it is produced in a sequential location that is appropriate not only for the interaction but also when it is possible for Mum to adequately produce the sound. The point of interest here is that while the LS chain makes chewing food relevant and can be done to share the moment of eating as a social activity, it also requires that the speaker coordinate their own chewing and swallowing of food with the social interaction and the sounds produced. While preparing for sounding in Extract 6, Mum maintains the infant's engagement through the continuing eye-gaze and close proximity between their faces. There is no other talk immediately surrounding either the gustatory $\mathrm{mmm}$ or the LS chain, and thus they primarily accompany and highlight the ongoing activity of eating in an alternative auditory modality, with the LS particles transforming the individual tasting and chewing of food into socially coordinated actions.

In the final example, Extract 7, we see further examples of how LS chains can be placed during a lull in the conversation and for which no further vocal sounds or talk is treated as relevant, but how an occasional eating sound by the infant can still be treated by parents as initiating actions to be responded to with LS chains, thus building sequences of turns-in-interaction (see a similar organization of outof-breath sounds; Pehkonen 2020). There are also lip-smacks made by the infant while they are holding their food and looking down at their tray (lines 03, 05, 08-16): the lack of gaze to another participant making them quite distinct from the parental LS particles. This sequence occurs in the middle of a meal during which the infant has been looking out of the window, occasionally moving their jaw. Mum is seated nearby, also eating, and has been gazing intensely at the infant.

\section{Extract 7. Lewiso11_0400}

$\begin{array}{lll}01 & \text { MUM } & \text { what do you see. } \\ 02 & & \begin{array}{l}(0.9) \\ \text { 03 }\end{array} \\ \text { INF } & \text { inf } & \begin{array}{l}\text { gaze on table, picking up food } \\ (0.3)\end{array} \\ 04 & & \begin{array}{l}(0.3)\end{array}\end{array}$




\section{\#im15}

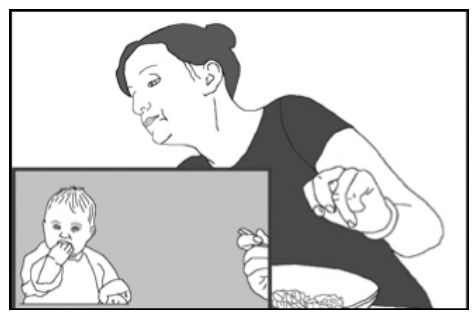

Image 15: looking behind

${ }^{\circ}$ no\#m ${ }^{\circ n}$.mts \&.mts .mts

${ }_{->^{\wedge}}$ ((arrives back from the bend)) -> \&gaze to window

\#im16

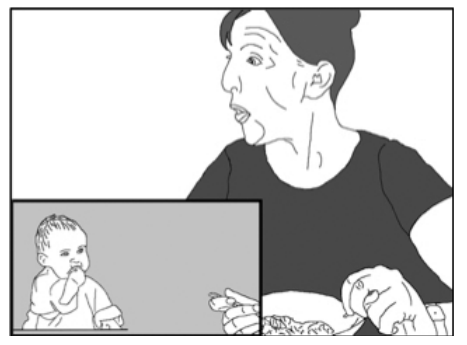

Image 16: first nom

$(0.6)^{\wedge}(0.6)$

\begin{tabular}{|c|c|}
\hline num & $->^{\wedge}$ gaze to her plate \\
\hline INF & $\begin{array}{l}. m p t a ̊ \\
(2.5)\end{array}$ \\
\hline INF & $\begin{array}{l}. \mathrm{mpt} \\
(2 . \theta)\end{array}$ \\
\hline INF & \&.mt \\
\hline inf & $\begin{array}{l}\text { \&opens mouth but drops food } \\
\text { (1.9) }\end{array}$ \\
\hline $\begin{array}{l}\text { INF } \\
\text { inf }\end{array}$ & .mt .mpta .mpta \&mk \\
\hline INF & $\begin{array}{l}\text { (2.3) } \\
\text { mt he : : : .mpt (0.3).mpta } \\
(1.1)\end{array}$ \\
\hline
\end{tabular}

While this sequence almost totally lacks words, there is still a lot of embodied and vocal activity both on the part of the infant and the parent. Though they are eating food from their own plates, the parent is carefully monitoring the infant's eating and at times entering into the interactional space through eye gaze and lipsmacks. Similar to Extract 5, in this example the infant's instrumental lip smacks seem to occasion an extended and exaggerated response by Mum in line 06. While the infant's LS particles are produced with gaze on the food, Mum's LS 
chain is launched after mutual gaze has been achieved. Furthermore, the labial articulatory bases of the LS particles make them quite easily reproducible as approximations by the infants of this age group, where labial sounds are known to occur (Sander 1972). This potential similarity in sounding makes the exchanges emerge as highly collaborative sequences, even though all kinds of sounds from the infant, including open vowels, can be treated as conversational contributions.

Parental LS chains are thus typically positioned with regard to the activities of both participants. As seen in Extracts 6 and 7, they can be produced while the parent is also eating though need to be coordinated with the mechanics of chewing and swallowing food. Mutual eye-gaze was an important feature of LS chains. In the example above, Mum bends slightly to one side to check if food has fallen from the infant's plate (see Image 14), and it is this motion that precedes the infant's eye gaze to Mum (see Image 15). It is only at that point, with mutual gaze, that the LS chain is produced. From these two examples and from the other cases seen in the data corpus, it becomes clear that although the lip-smack is a sound that is in principle omni-relevant during eating practices, there are specific moments in which parental LS chains become appropriate in relation to the local embodied behaviour of the participants. These are when the infant has food in their mouth, there is mutual eye-gaze between parent and infant (or at least parental eye-gaze on the infant), when the parent does not have food in the front of their mouths, typically following a brief period of silence and occasionally after an instrumental lip-smack from the infant.

Lip-smacks are useful elements of interaction with infants since they offer a respite from talking, while maintaining the ongoing activity and establishing sociality while eating. Lip-smacks commit neither the speaker nor other persons present to respond or comment while they afford turn-taking (see Gratier et al. 2015 on infant turn-taking with vocalizations already at the age of 2-5 months) and similar articulatory formatting of the "turns" across the asymmetrically capacitated participants. In the first instance, however, they contribute to the progressivity of eating and specifically to eating as a joint social occasion with a focus on the events in the mouth of the novice.

\section{Discussion}

The parental lip-smacks in this data corpus were found to have regular features of rhythm, facial-embodied aspects, and temporal organisation in relation to other actions. As a sound object that lies at the edge of language, it can be evidenced nonetheless to have social functions in terms of engagement in eating practices and the emergence of co-eating with a novice. Similar to the gustatory $\mathrm{mmm}$ 
that parents frequently use to encourage and positively evaluate taste (Wiggins \& Keevallik, 2021) the LS chains orient to the food but with a focus on eating as a mechanical accomplishment through their positioning at moments when the infant either already is, or should be, moving their lips and jaws. The parents thereby as if join in the embodied eating procedures of the infant, encouraging and endorsing them in real time. LS chains furthermore enable rudimentary turntaking in a similar sound form between the parent and the infant, as parents regularly build on infants' instrumental eating sounds by enhancing them through repetition, increased loudness, and rhythmical patterns. Close mutual engagement emerges during these sounding interactions, as facial and postural behaviours are used to diminish physical distance and display a positive stance towards the activity. Finally, LS chains can be used to index eating, even when it is not currently happening. They seem to be conventionally tied to the activity so that they can serve as explanatory means for young infants regarding the use of, for example, a spoon.

The analysis presented here contributes to a number of research fields. First, it develops work on non-lexical sounds, providing further evidence that these are intricately co-ordinated with bodily movements and concerns in social interaction (Keevallik, 2018; Keevallik \& Ogden, 2020; Reber \& Couper-Kuhlen, 2020). Our focus was on the repetitiveness and rhythmicality of the lip-smacks and the relevance of LS chains for creating mutual engagement with an embodied practice such as eating. Similar to the Finnish sound huh huh, LS particles are reflective of individual bodily experiences but can be treated as initiating actions to be responded to by others invested in the same activity (Pehkonen, 2020). These engagements reflect early patterns of sociality in an infant's life. Second, we contribute to work on sensory practices and particularly to that which focuses on eating as a series of connected events, from sniffing (Mondada, 2020) to tasting (Mondada, 2018; Wiggins, 2019; Wiggins \& Keevallik, 2021). The lipsmack focuses attention particularly on the chewing and manipulation of food in the mouth. Similar to Ogden's work on clicks which noted that they demonstrate an orientation to the relevance of talk without actually saying anything (Ogden, 2020), we might argue that lip-smacks do the same with regards to displaying an orientation to the relevance of eating and particularly, the chewing of food, rather than the relevance of talk. Finally, the analysis resonates with nonhuman primate research on lip-smacks, while providing details about multimodal features and the specific social context within which these take place (c.f. Fedurak \& Slocombe, 2011; Fedurak et al., 2015). Ironically, while other primate research has noted that chimpanzee lip-smacks are similar to language due to their frequency and rhythm (Bergman, 2013; Pereira et al., 2020), human lip-smacks as produced in this infant meal context are partially dissimilar to speech. They fea- 
ture a percussive and repetitive rhythm that stands out against the melodic nature of surrounding talk. Like the clapping of hands or the knocking on a door, they maintain a focus on the embodied activity trajectories. By showing that infant interaction likewise deploys lip-smacks for affiliative and positive engagements, we can suggest an interactional similarity in the use of this primitive sound across the species (see Pika et al. 2018, on turn-taking across the species). The relevance of the lip-smack as a means to engage novice eaters (infants) might indicate the potential to explore the use of related sounds in animal-human interaction such as when feeding pets. While the dataset for this exploratory study is contextually limited, cultural comparisons in the use of these sounds would be particularly exciting, since they do not require language to articulate but still require co-ordination of lips, tongue, and jaw movements and can thus potentially reveal universal patterns of mutual engagement.

In conclusion, this paper examines the multimodal features and social functions of a sound - the lip-smack - that has to date had limited research attention in human interaction. As a sound that focuses attention on the lips and jaws, it has the potential to open up further research on social interaction around eating practices. Furthermore, multimodal interaction analysis of contexts such as the above shows immense potential in broadening our horizons regarding the essence of human sociality, as it enables us to take into account not only linguistic objects but also the precise embodied and temporal organisation of non-lexical sounds that lie at the boundary between the body and language.

\section{Funding}

We are very thankful for funding support from the Swedish Research Council grant VR 2016o0827, "Vocal practices for coordinating human action".

\section{Acknowledgements}

We would like to extend our thanks to the participating families, to Annerose Willemsen for careful preparation of the anonymised images, to Richard Ogden for consultation on the spectrograms and to the journal editors and two anonymous reviewers for meticulous attention to detail.

\section{References}

Andersen, J. (2015). Now you've got the shiveries: Affect, intimacy, and the ASMR whisper community. Television \& New Media, 16(8), 683-700. https://doi.org/10.1177/1527476414556184 
Bennett, W.G. (2014). Some differences between clicks and labio-velars. South African Journal of African Languages, 34(2): 115-126. https://doi.org/10.1080/02572117.2014.997045

Bergman, T. (2013). Speech-like vocalised lip-smacking in geladas. Current Biology, 23(7), R268-269. https://doi.org/10.1016/j.cub.2013.02.038

Choe, H. (2019). Eating together multimodally: Collaborative eating in mukbang, a Korean livestream of eating. Language in Society, 48(2), 171-208. https://doi.org/10.1017/So047404518001355

De Marco, A., \& Visalberghi, E. (2007). Facial displays in young tufted capuchin monkeys (Cebus apella): Appearance, meaning, context, and target. Folia Primatol, 78, 118-137. https://doi.org/10.1159/000097061

Diepstra, H., Trehub, S., Eriks-Brophy, A., \& van Lieshout, P. (2017). Imitation of non-speech oral gestures by 8-month-old infants. Language and Speech, 60 (1): 154-166. https://doi.org/10.1177/0023830916647080

Fedurek, P., \& Slocombe, K. (2011). Primate vocal communication: A useful tool for understanding human speech and language evolution? Human Biology, 83(2): 153-173. https://doi.org/10.3378/027.083.0202

Fedurek, P., Slocombe, K., Hartel, J., Zuberbühler, K. (2015). Chimpanzee lip-smacking facilitates cooperative behaviour. Nature Publishing Group, 5, 1-7. https://doi.org/10.1038/srep13460

Fele, G., \& Liberman, K. (2021). Some Discovered Practices of Lay Coffee Drinkers. Symbolic Interaction, 44 (1), 40-62. https://doi.org/10.1002/symb.486

Ferrari, P., Paukner, A., Ionica, C., \& Suomi, S. (2009). Reciprocal face-to-face communication between rhesus macaque mothers and their newborn infants. Current Biology, 19(20), 1768-1772. https://doi.org/10.1016/j.cub.2009.08.055

Ferrari, P., Visalberghi, E., Paukner, A., Fogassi, L., Ruggiero, A., \& Suomi, S. (2006). Neonatal imitation in rhesus macaques. PLoS biology, 4(9), e302. https://doi.org/10.1371/journal.pbio.0040302

Ghazanfar, A., Morrill, R., \& Kayser, C. (2013). Monkeys are perceptually tuned to facial expressions that exhibit a theta-like speech rhythm. PNAS, 110(5), 1959-1963. https://doi.org/10.1073/pnas.1214956110

Ghazanfar, A. \& Takahashi, D. (2009). Facial expressions and the evolution of the speech rhythm. Journal of Cognitive Neuroscience, 26 (6), 1196-1207. https://doi.org/10.1162/jocn_a_00575

Ghazanfar, A., Takahashi, D., Mathur, N., \& Tecumseh Fitch, W. (2012). Cineradiography of monkey lip-smacking reveals putative precursors of speech dynamics. Current Biology, 22(13), 1176-1182. https://doi.org/10.1016/j.cub.2012.04.055

Goodwin, C. (2000). Action and embodiment within situated human interaction. Journal of pragmatics, 32(10), 1489-1522. https://doi.org/10.1016/So378-2166(99)00096-X

Gratier, M., Devouche, E., Guellai, B., Infanti, R., Yilmaz, E. \& Parlato-Oliveira, E. (2015). Early development of turn-taking in vocal interaction between mothers and infants. Frontiers of Psychology, 6,1167. https://doi.org/10.3389/fpsyg.2015.01167

Hjalmarsson, A. (2011). The additive effect of turn-taking cues in human and synthetic voice. Speech Communication, 53(1), 23-35. https://doi.org/10.1016/j.specom.2010.08.003

Hoey, E.M. (2014). Sighing in interaction: Somatic, semiotic, and social. Research on Language and Social Interaction, 47(2), 175-200. https://doi.org/10.1080/08351813.2014.900229 
Hofstetter, E. (2020). Nonlexical “Moans”: Response Cries in Board Game Interactions. Research on Language and Social Interaction, 53(1), 42-65. https://doi.org/10.1080/08351813.2020.1712964

Keevallik, L., \& Ogden, R. (2020). Sounds on the Margins of Language at the Heart of Interaction. Research on Language and Social Interaction, 53(1), 1-18. https://doi.org/10.1080/08351813.2020.1712961

Ladefoged, P., \& Traill, A. (1994). Clicks and their accompaniments. Journal of Phonetics, 22(1), 33-64. https://doi.org/10.1016/Soo95-4470(19)30266-9

Li, Y., He, Q., Li, T., \& Wang, W. (2008). A detection method of lip-smack in spontaneous speech. 2008 International conference on audio, language, and image processing, IEEE, 292-297.

Locke, J.L. (2008). Lipsmacking and babbling: Syllables, sociality, and survival. In B. L. Davis \& K. Zajdó (Eds.), The syllable in speech production (p. 111-129). Taylor \& Francis Group.

MacNeilage, P.F. (2008). The origins of speech. Oxford: Oxford University Press.

Maestripieri, D. (1996a). Gestural communication and its cognitive implications in pigtail macaques (Macaca nemestrina), Behaviour, 133, 997-1022. https://doi.org/10.1163/156853996Xoo576

Maestripieri, D. (1996b). Social communication among captive Stump-Tailed Macaques (Macaca arctoides). International Journal of Primatology, 17(5), 785-802. https://doi.org/10.1007/BFo2735264

Micheletta, J., Engelhardt, A., Matthews, L., Agil, M., \& Waller, B. M. (2013). Multicomponent and multimodal lip smacking in crested macaques (Macaca nigra). American Journal of Primatology, 75 (7), 763-773. https://doi.org/10.1002/ajp.22105

Mondada, L. (2011). Understanding as an embodied, situated and sequential achievement in interaction. Journal of Pragmatics, 43(2), 542-552. https://doi.org/10.1016/j.pragma.2010.08.019

Mondada, L. (2018). The multimodal interactional organization of tasting: Practices of tasting cheese in gourmet shops. Discourse Studies, 20(6), 743-769. https://doi.org/10.1177/1461445618793439

Mondada, L. (2020). Audible sniffs: Smelling-in-interaction. Research on Language and Social Interaction, 53(1), 140-163. https://doi.org/10.1080/08351813.2020.1716592

Negayama, K. (1993). Weaning in Japan: A longitudinal study of mother and child behaviours during milk- and solid-feeding. Early Development and Parenting, 2(1), 29-37. https://doi.org/10.1002/edp.2430020106

Ogden, R. (2013). Clicks and percussives in English conversation. Journal of the International Phonetic Association, 43(3), 299-320. https://doi.org/10.1017/So025100313000224

Ogden, R. (2020). Audibly not saying something with clicks. Research on Language and Social Interaction, 53(1), 66-89. https://doi.org/10.1080/08351813.2020.1712960

Pehkonen, S. (2020). Response cries inviting an alignment: Finnish huh huh. Research on Language and Social Interaction, 53(1), 19-41. https://doi.org/10.1080/08351813.2020.1712965

Pereira, A., Kavanagh, E., Hobaiter, C., Slocombe, K.E., \& Lameira, A. R. (2020). Chimpanzee lip-smacks confirm primate continuity for speech-rhythm evolution. Biology Letters, 16 (5), 20200232. https://doi.org/10.1098/rsbl.2020.0232

Pika, S., Wilkinson, R., Kendrick, K. \& Vernes, S.C. (2018). Taking turns: bridging the gap between human and animal communication Proc. R. Soc. B.28520180598. https://doi.org/10.1098/rspb.2018.0598 
Reber, E. (2012). Affectivity in interaction: Sound objects in English. Amsterdam: John Benjamins. https://doi.org/10.1075/pbns.215

Reber, E. \& Couper-Kuhlen, E. (2020). On "Whistle” Sound Objects in English Everyday Conversation. Research on Language \& Social Interaction, 53 (1), 164-187. https://doi.org/10.1080/08351813.2020.1712966

Sander, E. K. (1972). When are speech sounds learned? Journal of Speech and Hearing Disorders, 37(1), 55-63. https://doi.org/10.1044/jshd.3701.55

Schegloff, E.A. (1996). Turn organization: One intersection of grammar and interaction. Studies in interactional sociolinguistics, 13, 52-133. https://doi.org/10.1017/CBO9780511620874.002

Slocombe, K., Waller, B., \& Liebal, K. (2011). The language void: The need for multimodality in primate communication research. Animal Behaviour, 81(5), 919-924. https://doi.org/10.1016/j.anbehav.2011.02.002

Toyama, N. (2013). Japanese mother-infant collaborative adjustment in solid feeding. Infant Behaviour and Development, 36(2), 268-278. https://doi.org/10.1016/j.infbeh.2013.01.008

van de Waal, E., Spinelli, M., Bshary, R., Hausbar Ros, A. F., \& Noë, R. (2013). Negotiations over grooming in wild vervet monkeys. International Journal of Primatology, 34, 1153-1171. https://doi.org/10.1007/s10764-013-9729-1

Wiggins, S. (2019). Moments of pleasure: A preliminary classification of gustatory $\mathrm{mmms}$ and the enactment of enjoyment during infant mealtimes. Frontiers in psychology, 10, 1404. https://doi.org/10.3389/fpsyg.2019.01404

Wiggins, S., \& Keevallik, L. (2021). Enacting Gustatory Pleasure on Behalf of Another: The Multimodal Coordination of Infant Tasting Practices. Symbolic Interaction, 44(1), 87-111. https://doi.org/10.1002/symb.527

Wright, M. (2011a). On clicks in English talk-in-interaction. Journal of the International Phonetic Association, 41(2), 207-229. https://doi.org/10.1017/S0025100311000144

Wright, M. (2011b). The phonetics-interaction interface in the initiation of closings in everyday English telephone calls. Journal of Pragmatics, 43(4), 1080-1099. https://doi.org/10.1016/j.pragma.2010.09.004

\section{Address for correspondence}

\section{Sally Wiggins}

Department of Behavioural Sciences and Learning

Linköping University

Campus Valla

Linköping, 58183

Sweden

sally.wiggins.young@liu.se

https://orcid.org/oooo-0oo2-3307-0748 


\section{Co-author information}

Leelo Keevallik

Department of Culture and Society

Linköping University

leelo.keevallik@liu.se

\section{Publication history}

Date received: 15 February 2021

Date accepted: 18 June 2021

Published online: 2 August 2021

Corrected: 16 August 2021

In the original Online-First version of this article published on 2 August 2021, Tables 3 and 4 and Extracts 1-7 were not properly formatted. These have been updated in the current version of the article. 